\title{
Integrated Resource and Order Monitoring
}

\author{
H.-P. Wiendahl, J. Gläßner, M. Mittendorf \\ Institute for Production Systems (IFA), University of Hannover \\ Callinstr.36, 30167 Hannover, Germany \\ Telephone: + $49511762-2440$ \\ FAX: $\quad+49511762-3814$ \\ E-mail:_mit@thor.ifa.uni-hannover.de
}

\begin{abstract}
Growing global competition forces enterprises to improve their logistic quality to ensure customer satisfaction. Logistic quality requires good process capability as well as high process reliability. One approach for establishing a high logistic quality is the application of logisticoriented and computer-aided monitoring systems, based on logistic models (e.g. the funnel model, developed at the IFA). This model describes and quantifies the dynamic interactions between logistic objectives.

To assist the creation of a company-specific balance between the contradictory logistic targets, monitoring systems have to provide an order-oriented and a resource-oriented view of logistic processes. With the regular processing and visualisation of logistically relevant information corresponding to these views, this integrated monitoring concept supports various logistic analyses and the derivation of improvement measures.
\end{abstract}

\section{Keywords \\ Production Model, Monitoring, Logistic Controlling}

\section{INTRODUCTION}

Competition forces the companies to strengthen their market power by improving their performance. Besides innovative solutions and high product quality, logistic efficiency is an important aspect for market success. The logistic efficiency can be described by delivery capability and delivery performance.

The delivery capability describes the ability of a company to promise a customer a certain desired deadline in consideration of the production situation. Delivery performance, on the other side, is the extent to which delivery dates promised at the placing of the order are met. If the desired delivery performance has been realized, process control exploits this logistic potential within the scope of resources planning, inventory management and operative control 
to realize a high logistic process reliability. Besides the mentioned performance indicators, to ensure market success, product prices and therefore the economic efficiency of all business processes must not be ignored.

Mainly by applying production planning and control, it is aimed to carry out the logistic objectives mentioned above. But as the systems used in companies often offer only insufficient support for these tasks the result is frequently unsatisfactory. Extensive analyses carried out by the IFA in various companies have shown that in most cases the deadlines are not met and there is often a lack of process reliability. Therefore many enterprises are very dissatisfied with the used PPC systems (Hautz, 1993). According to a survey carried out by GEIGER $77 \%$ of 70 German medium-sized companies named PPC as the main source of problems in production (Glaser, 1991).

\section{REQUIREMENTS FOR A SYSTEM FOR INTEGRATED ORDER AND PROCESS MONITORING}

\subsection{Integration into the planning and control process}

A basic approach to improve this stuation is to provide logistic-oriented instruments for the controlling of the production processes. They should already consider interdependencies between the logistic objectives and facilitate statistically based statements about the aspired targets using key data and process graphics.

By using appropriate data processing and representation measures, a target-oriented process structuring and control can be derived along the logistic chain with these monitor systems, if

- the used key data correspond to the figures relating to quantity and time normally used in planning,

- the resource and order-related approach to the production process necessary for planning and control is supported and

- the supply of information is geared to the different questions concerning the strategic, materials planning and scheduling and operative level of planning.

Then the control of logistic processes can be transformed into a "closed-loop control" via the feedback element "monitor system" which is a main condition for a logistically regulated production process. To sum up, it can be said that monitor systems provide support for the following tasks:

- Target-oriented review and adaptation of the product and production structure.

- Deduction of realistic rated values for the planning of the order delivery date and the monitoring of order throughput.

- Continuous depiction of the actual status adapted to the information requirement of the various decision-makers.

- Analysis of deviations by rated-to-actual comparisons.

- Derivation of measures for process improvement. 


\subsection{Necessary monitoring approaches}

To fulfil the above mentioned tasks, monitor systems have to support two approaches to the logistic procedures corresponding to the schedule and loading plan of a PPC system, these being an order-oriented and a resource-oriented approach.

The targets delivery performance and delivery time can be monitored by means of the order-oriented approach to the order throughput of a company. If the production is mainly customer-specific these targets determine directly the company's market success. The change in importance of the objectives as a function of the position of the point of customer decoupling and the procurement strategies belonging to it. Generally a part of the production process has to be realized on the basis of a production program, that is producing to stock, because normally the delivery time required by the market is shorter than the lead time needed for procurement, manufacturing and assembly of the whole product. Before the point of customer decoupling, the inventory as well as the utilization of the means of production come to the fore.

For companies in the capital goods industry, where the process of product development is largely customer-specific, order monitoring is of great importance. In case of customeranonymous production the dimensionalization and continuous monitoring of the inventory and work systems - that is resource-oriented monitoring (see below) - come to the fore.

Depending on the level where the order monitoring is to support decision making, the system has to provide information with different levels of condensation:

- The rating of product structures according to the resulting logistic characteristics such as product structure lead time, point of variant formation, or the course of added value.

- The monitoring of the order network throughput.

- The monitoring of the throughput of individual procurement, manufacturing or assembly orders.

In addition to the order-oriented approach a resource-oriented monitoring for the order management is also necessary. Here the focus is not on the throughput of defined, mainly multi-stage, customer orders along the logistic chain, but rather on the logistic behavior of individual work centers within the procurement, manufacturing and assembly. In case of complex construction and operation scheduling processes, a development monitoring related to the work stations in non-manufacturing areas is necessary to support the order management.

The monitoring of work-system-related objectives like inventory, lead time, schedule performance and utilization reveals the quality of the individual logistic processes. If it is possible to control these key data via a closed-loop control, the market objectives delivery time and delivery performance can be influenced. Individual orders can be accelerated during throughput, for example by giving priority, but this has a negative effect on other orders, so that their key data deteriorate correspondingly. Thus there is a direct connection between the achievement of the objectives related to work system and order-related objectives. Only the control of the logistic procedures on every production process level guarantees the achievement of short delivery times and high delivery performance of the customer orders while at the same time considering the economic efficiency of the production process. 


\section{MODEL FOR A UNIVERSALLY APPLICABLE DEPICTION OF LOGISTIC PROCEDURES}

The basis for the outlined monitoring concept must be a universally applicable process model that shows realistically the planned and actual order throughput and supports logistic processes from both the resource-related and the order-related points of view. In order to depict the interaction between the processing behavior of work systems and the throughput behavior of individual orders a logical linking of the resource-related and the order-related process model is required.

A further prerequisite is that all logistic objectives with their reciprocal relations can be depicted in the model as well as in a corresponding key data system. Finally a graphic and numerical representation of the logistic procedures based on common operational data has to be guaranteed.

\subsection{Resource-oriented descriptive model}

The funnel model developed at the IFA is a universally applicable model for the representation of resource-related logistic processes. Initially this model was developed to depict the throughput behavior of manufacturing systems but it is also suitable for depicting logistic processes in general (Wiendahl, 1987).

As shown in Figure 1, the basic idea is to consider the work systems involved in the order processing as a network of interlinked funnels, based on the material flow. To a work system described in this way, orders come and go with the waiting orders representing the work-inprocess in the funnel. This process can be described quantitatively in the throughput diagram. As shown at the top right hand side of Figure 1, input and output of orders are plotted cumulatively as a function of time, beginning at a defined level of work-in-process. Here the value of the ordinate equals the size of the order, which is typically scaled in standard hours.

Depending on the definition of the system limits, the order throughput of an individual work station, a store or even a whole production sector can be represented. All main logistic objectives can be represented in the throughput diagram. The mean range corresponding to the lead time (defined as mean inventory divided by mean performance) and the mean inventory demonstrate, as shown in Figure 1, the vertical and horizontal distance respectively between the input and output curves. The mean performance can be determined by the gradient of the output curve. Schedule performance and utilization can also be shown, if the rated curves are depicted besides actual input and output.

The main purpose of the throughput diagram is to describe the dynamic process. It can be supplemented by a stationary description of the logistic behavior of work systems through logistic operating curves (Figure 1 at the bottom, right). Logistic operating curves condense various stationary operating states of a work system as a function of a parameter - the mean inventory - and show the functional relations between the logistic objectives of performance, range, lead time and interoperation time and the inventory (Nyhuis, 1991).

By using a logistic operating curve it can be shown that there are only small performance variations above a certain level of inventory. An interruption in work does not arise for there is a continuous supply of work. Below this value performance losses increasingly occur because of a temporary lack of work supply. Above a certain inventory level with almost 

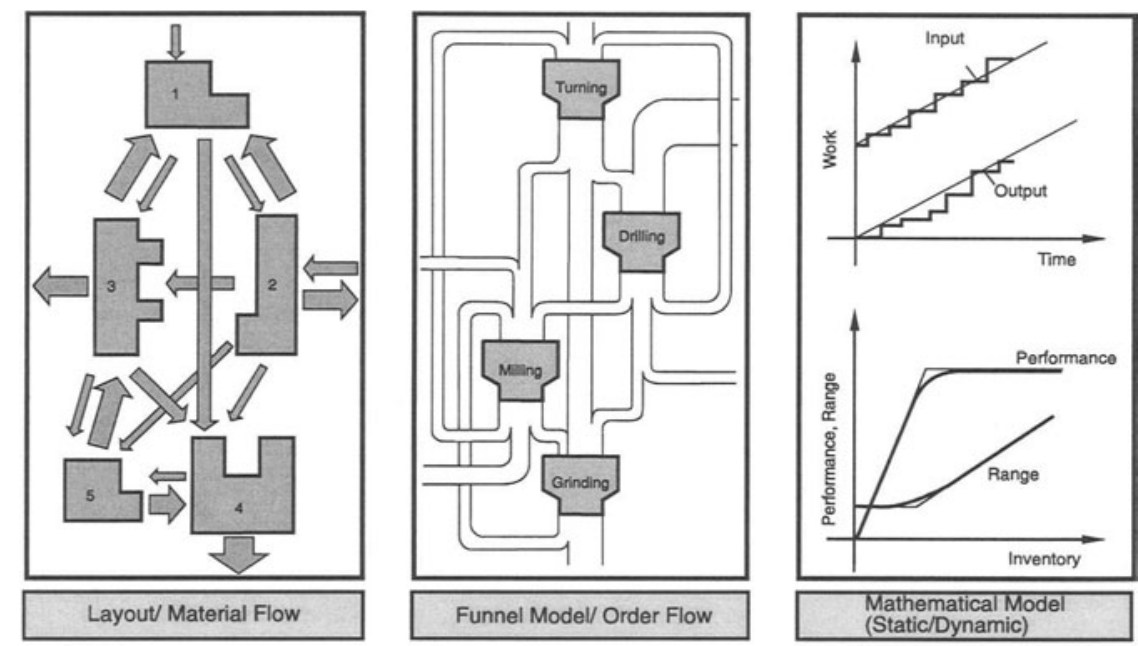

(c) IFA C0111E

Figure 1 Resource-oriented modelling of logistic processes.

constant performance the lead time increases corresponding to the work-in-process. Below this value the lead time decreases with a decreasing inventory to a theoretical minimum which only depends on the mean order time and transit time (Nyhuis, 1991).

On the whole the basic form of a logistic operating curve is valid for all production systems. Beside the determination based on simulation studies, there is the possibility to determine these curves using a mathematical approximation, as described by Nyhuis (1991, 1994a and 1994b) and Wiendahl (1991b).

\subsection{Order-oriented descriptive model}

A basis for describing a throughput of customer orders, which can consist of a network of individual orders, is an assembly-oriented product structure. This structure determines the components, parts and procurement items with their corresponding production stages which are necessary for the making of a product (see Figure 2 at the top). Therefore it forms the basis for the structure of the order network that covers all the requirements necessary for the making of the desired product as a customer order. Now the order network can be represented as a time schedule under the course of the time (middle part of Figure 2). Every order is shown as a bar, the length of which represents the order's lead time. In this representation the sequence of orders results from the logical dependencies in the order network so it can be seen which manufacturing and procurement orders have to be completed before starting a particular assembly order. 

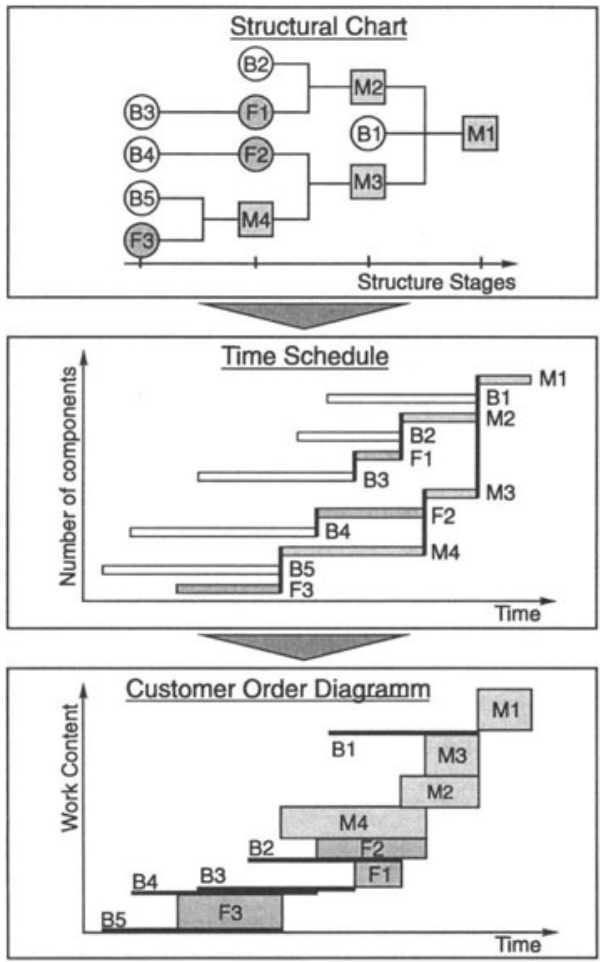

M: Assembly Component F: Manufacturing Part B: Procurement Item

(C) IFA C0611b_E

Figure 2 Derivation of the customer order diagram from the product structure.

As shown in the bottom part of Figure 2, a customer order throughput diagram is realized in such a way that the individual procurement, manufacturing and assembly orders of a customer order are classified by the completion date and plotted cumulatively as a function of time (Dombrowski, 1990). A throughput element is described as a rectangle. Its length represents the lead time and its height shows the size of the order. The cumulated work content of all working processes of manufacturing and assembly orders characterizes the size of the order. Since procurement items require virtually no capacity in the company concerned, they are merely represented as a bar in the diagram according to their respective replacement time. Thus the customer order throughput diagram illustrates the chronological procedure as well as the work content of all individual orders belonging to the customer order. Since the model has also to be suitable for the monitoring of individual manufacturing and assembly orders, as shown in Section 2.1, every throughput element of a customer order can be split up into its individual operations on the next lower hierarchic stage. 


\subsection{Interlinkage of both approaches}

Since the operation throughput elements are the basis of the resource-related throughput diagram, a transferable representation of the logistic behavior of customer orders and work systems is possible. The relation between the description of work-system-specific logistic processes in the throughput diagram and the order-oriented depiction in the form of a customer order throughput diagram is shown in Figure 3 using as an example the throughput of 5 manufacturing orders through 4 work systems.

The throughput diagram for work system 2 (Figure 3 below) shows the input- and outputbehavior of all the orders passing through this sector. Compared to this, the order throughput diagram represented on the left shows the throughput of order $\mathrm{C}$ with its 4 operations. The operation $\mathrm{C} 2$ at machine 2 is shown as a throughput element in both representations providing a connection between the order-oriented and the resource-oriented approach to logistic processes, so that the prerequisite for the integrated monitoring approach is given.

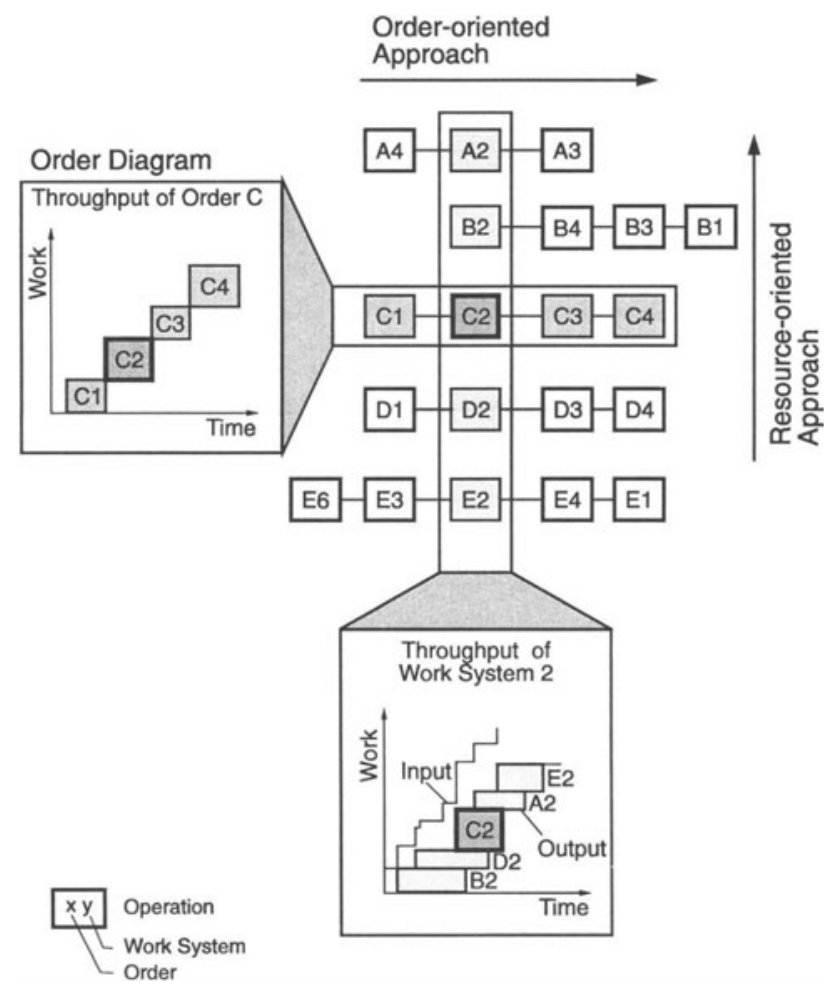

(C) IFA C0563b_E

Figure 3 Interlinkage of the resource and the order-oriented approach to logistic processes. 


\section{STRUCTURE OF AN INTEGRATED ORDER AND PROCESS MONITORING}

Figure 4 shows the classification aspects of an integrated order and process monitoring. It supports a resource-oriented and an order-oriented approach and enables the processing and representation of information adapted to the specific problems and planning horizons of the long, medium and short term planning stages (Wiendahl, 1992). Depending on the specific problem, the user is provided with flow charts, distributions and key data for the various approach levels.

For strategic decision making, analyses at long intervals are sufficient. They serve to check the logistic process capability, that is to examine to what extent the existing product and process structures allow the meeting of deadlines required by the market. As shown in the top of Figure 4, this can be realized on the resource side by demonstrating with logistic operating curves the marginal lead times that can be achieved while applying the existing or a new material flow structure, and considering a suitable utilization. The marginal lead times determined in that way can further be used to determine the shortest possible product lead time within the order-oriented approach. This information can be used, for example, to determine the point of customer decoupling (see Figure 2), to support a make-or-buy decision or to evaluate new products logistically. In this way aspects of a logistically suitable construction can be taken into account in the design and planning phase of the products.

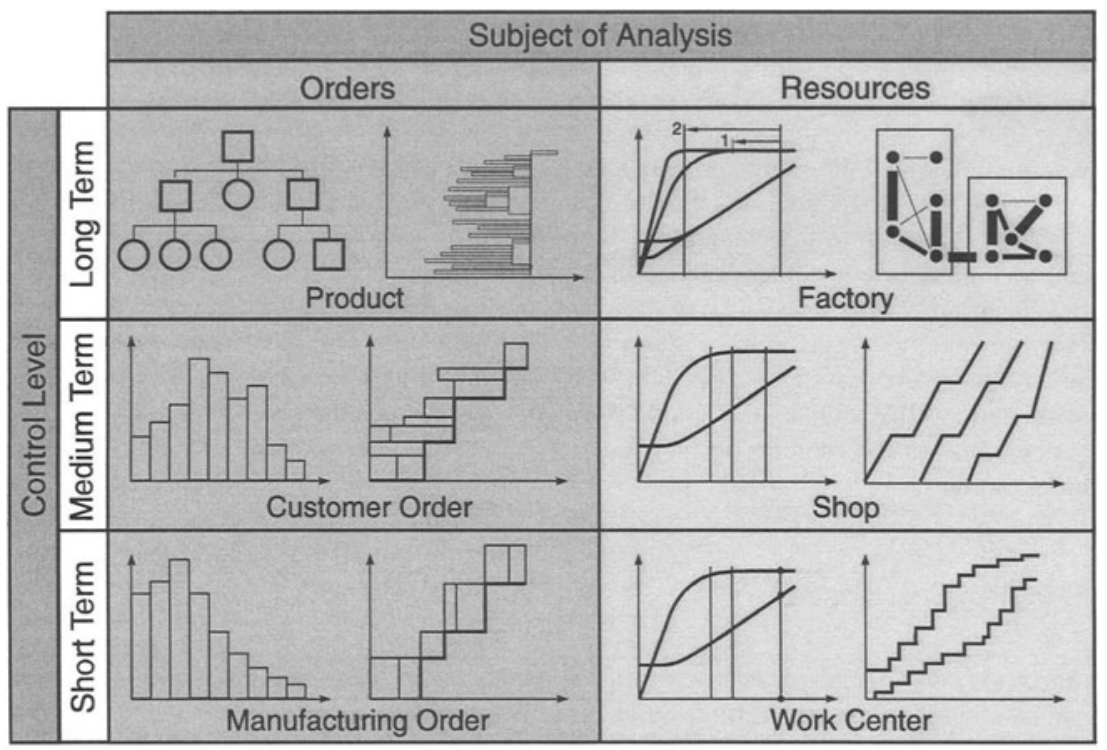

\section{OIFACO307E}

Figure 4 Classification aspects of an integrated resource and order monitoring. 
Monitoring systems on the operative level serve as a feedback within the flow regulation by continuously monitoring the logistic process reliability. This enables a visualization and validation of planning parameters such as the scheduled lead time. Finally customer order throughput diagrams and evaluations for the analyses of the order structure serve to monitoring the throughput of order networks and in this way support a customer order control. Structure analyses and order diagrams based on individual operations are applied to plan the throughput and to survey short-term orders in a certain section. In the resource-oriented approach the state at the work systems can be visualized with logistic operating curves and throughput diagrams. In case of an unstatisfactory actual status the finding of corrective measures is supported.

The presented concept is to be realized in the form of individual systems which on the one hand are based on a universal approach and particularly on a consistent process model and which on the other hand meet the specific interests of the various departments of the company. The order monitoring is an exception, for it surveys the inter-departmental aspect of the throughput of complete order networks. In this way it supplements the specialised process monitoring.

\section{SUMMARY}

Logistic controlling is required to guarantee the logistic quality and efficiency of a company. It controls the process capability as well as the logistic process reliability. One way to realize these requirements is to apply logistic-oriented and computer-assisted monitoring systems which have to support both logistic approaches, order-related and resource-related. With the regular processing and visualisation of logistically relevant information corresponding to these views, this integrated monitoring concept supports various logistic analyses. On this basis the development and derivation of improvement measures and the structuring and control of processes and procedures are supported. Therefore this monitoring concept is a useful tool to enhance a company's customer orientation and market performance.

Besides prototypical solutions developed at the IFA (Wiendahl, 1995) there are monitoring systems to monitor logistic procedures already available. These systems (developed in different ways) are based on the described methods and applied in a great number of companies (e. g. (Holzhüter, 1990) and (Wiendahl, 1991)). For the time being the main fields of application are the monitoring of manufacturing procedures as well as procurement and inventory monitoring.

\section{REFERENCES}

Dombrowski, U. (1990) Logistische Produktanalyse als Ausgangsbasis für eine Reorganisation des gesamten Auftragsdurchlaufs. Wiendahl, H.-P. (eds.): Belastungsorientierte Fertigungssteuerung. Seminar of the Institut für Fabrikanlagen, University of Hannover, 10./11.10.1989 in Hannover and 21./22.3.1990 in München.

Glaser, H., Geiger, W., Rohde, V., (1991) PPS, Grundlagen-Konzepte-Anwendungen. Gabler, Wiesbaden. 
Hautz, E. (1993) PPS und Logistik, zukünftig ein Widerspruch? In: H.-P. Wiendahl (Hrsg.): Conference IFA-Kolloquium 1993: Neue Wege der PPS. Institut für Fabrikanlagen, University of Hannover, gfmt-Verlags KG, München.

Holzhüter, E. (1990) Erfahrungen mit dem System KPSF zur belastungsorientierten Fertigungssteuerung in einem Maschinenbauunternehmen mittlerer Größe. In: H.-P. Wiendahl (Hrsg.): Belastungsorientierte Fertigungssteuerung. Dokumentation of seminar and conference of the Institut für Fabrikanlagen, University of Hannover, 21./22.3.1990, München.

Nyhuis, P. (1991) Durchlauforientierte Losgrößenbestimmung. Dissertation Universität Hannover 1991. Fortschritt-Bericht VDI, Reihe 2 Nr. 225, VDI-Verlag, Düsseldorf .

Nyhuis, P. (1994) Quantifizierung logistischer Rationalisierungspotentiale mit Betriebskennlinien. ZfB Zeitschrift für Betriebswirtschaft, Betriebswirtschaftlicher Verlag Dr. Th. Gabler GmbH, Wiesbaden, 64 (1994), H. 4, 443-464.

Nyhuis, P. (1994) Logistic operating curves - a comprehensive method of rating logistic potentials, Paper at conference "EURO XII / OR 36", University of Strathclyde, Glasgow.

Wiendahl, H.-P. (1987) The throughput diagramm - a universal model for illustration, control and supervision of logistic processes, Annals of the CIRP, Vol. 37/1/1987

Wiendahl, H.-P. (1990) PPS-Controlling - Grundgesetze einer logistikgerechten Produktionsplanung und Fertigungssteuerung. Paper at conference "7. Österreichischer LogistikDialog", Wien 1990.

Wiendahl, H.-P. (eds.) (1991) Anwendung der belastungsorientierten Fertigungssteuerung. Carl Hanser Verlag, München; Wien.

Wiendahl, H.-P., Kuprat, Th, (1991) Logistic Analysis of Production Processes by Operating Curves, Annals of the CIRP, Vol. 40/1/1991.

Wiendahl, H.-P., Ludwig, E., Ullmann, W. (1992) Produktions-Controlling - ein neuartiger Baustein zur Verbesserung der Fertigungsabläufe. Paper at conference "PPS im Wandel", 6./7. Okt. 1992, Zürich.

Wiendahl, H.P., Gläßner, J., Mittendorf, M. (1995) Integrated Resource and Order Monitoring, Paper at IFIP WG 5.7 working conference "Re-engineering the Enterprise", 20./21. April, 1995, Galway. 